\title{
Unreflective Partisans? Policy Information and Evaluation in the Development of Partisanship
}

\author{
Ted Brader
}

University of Michigan

Joshua A. Tucker

New York University

\begin{abstract}
What factors enable and motivate citizens to form partisan identities? Popular accounts, as well as several major theoretical approaches, attribute a central role for policy and ideological concerns in shaping the partisan orientations of voters. Information about the policy aims of parties should therefore, on average, make it easier for an individual to find a party that best fits her views, especially if she had previously been less familiar with the parties. The evidence for this is mixed, however. Plenty of studies find a robust correlation between policy views and partisanship. Yet there is mounting evidence that citizens look to parties to decide where to stand on policy issues, suggesting that partisan identification precedes policy preferences. We bring new evidence to bear by investigating directly the impact of substantive policy information on the partisan identities of ordinary citizens. To do this, we carry out a pair of original experiments across six countries, five of which are relatively young or unstable party systems. One experiment informs citizens about the policy goals of the major parties; we find little to no evidence that such information affects levels of partisanship. The other experiment tests the impact of inviting citizens to evaluate and compare their own position to the positions of the major parties, a more direct test of the sort of reasoning posited in some theoretical accounts. We find that this reflective task in fact depresses levels of partisanship, perhaps especially among those who knew less about politics and parties from the outset. This suggests that thinking about policy differences and proximities pushes citizens away from partisan attachments they form in the ordinary course of life, perhaps because such thinking generates fresh doubts or focuses attention on facets of partisan choice that matter less in typical processes of preference formation.
\end{abstract}

KEY WORDS: partisanship, party identification, experiments, experimental analysis, Russia, Poland, Hungary, Great Britain, Bulgaria, Moldova

Many citizens in democracies around the world readily confess to being adherents of a particular political party, and they tend to behave in a host of predictable ways-lining up their votes, evaluations of government, policy positions, and even perceptions of reality to match those of the party (Johnston, 2006; Lewis-Beck, Jacoby, Norpoth, \& Weisberg, 2008; Jacoby, 2011). Such partisanship is one of the most powerful and reliable sources of influence in democratic politics (Green, Palmquist, \& Schickler, 2002). But what factors enable and motivate citizens to form partisan identities, or to feel more or less attached to a particular party, in the first place? Why do some citizens develop these feelings of belonging while others do not? 
Popular accounts, as well as several major theoretical approaches, attribute a central role for policy and ideological concerns in shaping the partisan orientations of voters (Achen, 1992; Fiorina, 1981; Franklin \& Jackson, 1983). Parties, so the argument goes, are coalitions of candidates principally organized for the purpose of advancing certain policies or a particular vision of government (Aldrich, 1995). If that is the case, it makes sense for the affiliative decisions of ordinary citizens to be driven in large measure by how attractive they find those policies or visions. Information about the policy aims of parties should therefore, on average, make it easier for an individual to find a party that best fits her views, especially if she had previously been less familiar with the parties.

The evidence for all of this is mixed, however. Plenty of studies find a robust correlation between policy views and partisanship (Highton \& Kam, 2011; Jackson, 1975; Lenz, 2012; Miller \& Shanks, 1996). Yet a growing number of experimental studies show that citizens look to parties to decide where to stand on policy issues, suggesting perhaps that partisan identification precedes—rather than follows from-policy preferences (Brader \& Tucker, 2012; Coan, Merolla, Stephenson, \& Zechmeister, 2008; Cohen, 2003; Druckman, 2001; Sniderman \& Hagendoorn, 2007). This shows up not just in experimental settings but also in the dynamics of national polls, which at times show dramatic swings in popular preferences when parties shift their positions. For example, those paying close attention to American public opinion lately have been subject to quite a roller coaster ride. Think Republicans in the United States are more supportive of free trade, more favorable toward clandestine intelligence services such as the CIA, and more hostile to those who betray American secrets such as the WikiLeaks organization? Not anymore. Republican Party identifiers have shifted their views dramatically on these topics over the past couple of years from the positions traditionally adopted by the party and its leaders to the views espoused regularly by the party's new leader, President Donald Trump.

Although much ink continues to be spilt on the topic of partisanship, there is much we still don't know about its origins and consequences. Scholars have devoted considerably more attention to the impact of partisanship and to predicting which party attracts this or that group of voters. Far less attention has fallen on explaining whether someone develops a partisan identity or what causes that identity to strengthen or weaken. The most extensive of such assessments have focused on the role of familial socialization in giving rise to partisan identities prior to adulthood and constraining partisanship throughout the life cycle (Greenstein, 1965; Jennings, Stoker, \& Bowers, 2009; Niemi \& Jennings, 1991; Zuckerman, Dasovic, \& Fitzgerald, 2007). Although those studies yield incredibly important insights about the nature of partisan identities, they also return us to central questions about origins. Where did the parents or other family members get their partisanship? What shapes identities among the first generation of citizens in a new democracy or party system? Socialization research has found evidence that partisanship often waxes and wanes in strength over the course of adulthood (though people rarely switch from one identity to another), but any evidence on the causes of such movement has been largely indirect and thus has said little about the potential for policy concerns and debates to cause shifts in partisanship.

Nonetheless, the notion persists, in both popular imagination and major theories of party identification, that party position taking and voter learning about the policy priorities of parties can help recruit and solidify partisan supporters. In this article, we bring new evidence to bear by investigating directly the impact of substantive policy information on the partisan identities of ordinary citizens. There are still other possible sources of partisan identities beyond family socialization and policy information, but investigation of multiple explanatory factors - which are not necessarily mutually exclusive - is beyond the scope of this study. We focus our search for evidence on the idea that partisanship springs from and is solidified by exposure to and reasoning about party positions on substantive matters of public policy, as suggested by lay political commentary and leading-especially instrumental (or "rational") — theories of party identification.

To do this, we carried out two different types of original experiments in surveys of broad crosssections of adult citizens. One experiment informs citizens about the policy goals of the major parties. 
The other experiment tests the impact of inviting citizens to evaluate and compare their own position relative to the positions of the major parties across three major policy domains, a more direct test of the sort of comparative and positional reasoning posited by leading accounts. We conducted one or both of these experiments in six countries, five of which were relatively young or unstable party systems at the time. We focus heavily on party systems in their formative stages as this is the sort of political environment where one might most expect policy evaluations to shape partisan identities. Parental socialization ought to be less relevant, thereby making way for a greater impact by other factors. Fewer citizens, regardless of age, will have had time to solidify a party identity. And parties themselves will be newer and their policy priorities less well known among the electorate. All of that said, we also carried out the experiments in one of the most venerable party systems in the world to facilitate at least an initial comparison of whether and how much these environmental considerations may matter.

\section{Policy Information and Evaluation in the Development of Partisanship}

For more than a half-century, scholars have considered party identification, or partisanship, the most important attribute explaining the political behavior of citizens (Campbell, Converse, Miller, \& Stokes, 1960; Johnston, 2006; Lewis-Beck et al., 2008). Partisanship is a latent predisposition to support a particular party. Some citizens even identify with a party, feeling a sense of social belonging with other supporters of the party and seeing this informal group membership as an important part of who they are. The power of partisanship serves as a "standing decision" in elections from which citizens must be persuaded to defect, but it also extends much further. Partisanship may serve as a heuristic in the formation of policy opinions, a motivational force preparing one to act on behalf of a party, a cognitive structure that organizes one's understanding of the political world, and a "perceptual screen" that can bias even one's factual beliefs about the world (Bartels, 2002; Lau \& Redlawsk, 2001; Lodge \& Hamill, 1986; Petersen, Skov, Serritzlew, \& Ramsøy, 2013; Slothuus \& de Vreese, 2010).

But from whence does this potent political identity come? Why do some people become fervent partisans and others do not? Early seminal works on the concept offered only vague sketches of the theoretical mechanism driving the development of partisanship. Scholars in the sociological tradition suggested that partisan predispositions are derivative of the historical layering of social group alignments, such as those tied to social class and religion (Berelson, Lazarsfeld, \& McPhee, 1954; Lazarsfeld, Berelson, \& Gaudet, 1944). Operating from a social psychological standpoint, researchers at the University of Michigan emphasized party identification as a psychological attachment to a particular party (Campbell et al., 1960). They also treated it as a core attitude shaped by signals from a person's immediate social environment and from secondary social groups and "crystallized" through the individual's own reinforcing thoughts and actions (Converse, 1969). In all of this early work, there may have been a general sense that policy issues and preferences lurked somewhere in the origin story of partisanship, but if so their role was buried deep in a history of social forces and elite political maneuvering that is remote from the contemporary psychological processes of the individual.

In direct response to this line of thought and its submersion of the issues seemingly at the heart of day-to-day politics, new models emerged that sought to place the study of partisanship on a more instrumental, or "rational," footing. If early work had stressed the long-term stability of party identities, this revisionist approach emphasized the fact that those identities can shift, if often gradually, and that the strength of partisanship can wax and wane. Revisionist scholars put evaluations of policy performance and promises front-and-center in their models, positing that partisanship is a "running tally" of one's feelings about different political parties that is constantly updated by new perceptions of the 
parties' policy positions and effectiveness in government (Achen, 1992, 2002; Fiorina, 1981; Franklin, 1984; Franklin \& Jackson, 1983; Jackson, 1975; MacKuen, Erikson, \& Stimson, 1989). ${ }^{1}$

Under this instrumental conceptualization, the more a person perceives the country, and especially people like themselves, as having fared better-in terms of the economy, foreign affairs, crime, and other domains - under the leadership of a particular party, the more likely she is to identify as a devotee of that party (Fiorina, 1981). Similarly, partisanship strengthens to the extent a person sees one party, as compared to others, as championing a set of policies that are more in line with her preferences and interests-what Achen $(1992,2002)$ describes as the anticipated differential stream of benefits, on average, across all issues. This conceptual innovation coincided with the development and spread of new survey instruments for measuring policy perceptions of the parties, such as domain-specific approval or handling questions ("which party would do a better job...") and placement questions asking individuals to place themselves and the major political parties on some fixed scale designed to reflect a range of ideological orientations or policy preferences in the American National Election Studies (ANES) and other surveys. The placement measures in particular are suited to evaluating instrumental and spatial models of policy reasoning by allowing researchers to compute the (perceived) proximity of each party to any given voter.

Revisionist scholars do not propose of course that individuals explicitly engage in comprehensive evaluations of the policy benefits likely to accrue from each party nor that they literally compute their relative distance from each party across one or several issues (unless asked to do so by survey researchers). Individuals nonetheless may come to recognize the policy virtues of one or another party by taking in bits of information piecemeal, over time, and may likewise accumulate a sense that they are closer to one party than others on the issues that matter to them. In that respect, the flow of information on party policies and opportunities to reflect on one's position vis-à-vis the parties ought to, on average, serve as building blocks in the development of partisan identities.

There are a number of other explanations for why some people are more partisan than others. As already noted, past research in the United States has pointed to the importance of parental socialization (Greenstein, 1965; Niemi \& Jennings, 1991; Zuckerman et al., 2007), as well as to high levels of political engagement (Campbell et al., 1960; Jennings et al., 2009; Shively, 1979) and behavioral reinforcement through habitually voting for the same party (Campbell et al., 1960; Converse, 1969). At the same time, many of these processes can be recast in terms of reasoning about instrumental policy benefits (Achen, 1992, 2002). More recently, scholars have drawn on social identity theory to interpret and measure partisanship (Gerber \& Green, 1998; Green et al., 2002; Huddy, Mason, \& Aarøe, 2015; Weisberg \& Greene, 2003). Although, again, less has been said about the implications of social identity theory for the origins of partisanship than its behavioral implications, this approach restores an emphasis on party identification arising from, or building on, more fundamental social identities. For example, a person is apt to embrace a particular partisan identity when he comes to recognize that "people like me"- as defined by religion, ethnicity, region, occupation, or some other shared attribute- tend to be supporters of that party (Green et al., 2002).

Although much can be said about all of these other explanations, including that they are not mutually exclusive, we focus in this article on examining the impact of policy information and reasoning on the development of partisanship. From this perspective, citizens judge the differential benefits of competing parties and update accordingly. We thus expect that, on average, if citizens learn more about political parties and where they stand on political issues, they ought to be more confident in which party is "their party." The same may be true even if the information is not new per se to the

\footnotetext{
${ }^{1}$ Although this view takes center stage in the revisionist models, it is not the case that researchers in the social psychological tradition fail to recognize any role for issues and performance in shaping party identities, especially among young adults (Campbell et al., 1960; Niemi \& Jennings, 1991).
} 
individual: Given how rarely politics is a primary focus for most voters, reminders of party policy positions and differences may also shore up partisan leanings. This leads to our first hypothesis.

H1: Exposure to information that distinguishes the policy positions and priorities of the major political parties in a country ought to increase the likelihood that individuals identify with a party and/or strengthen their expressions of partisanship.

It may be, however, that the impact of policy information on its own is negligible in the absence of deeper thought as to the meaning or significance of that information. Perhaps individuals must take what they know about the parties - either new details or perceptions already stored in memory-and use that information to reflect on which parties are closer to, versus more distant from, their own preferences. This process, whether it occurs all at once or intermittently over time, may be the key to individuals finding their way to a partisan identity. This leads us to a second hypothesis

H2: Prompting individuals to reflect on the proximity of the major political parties in a country to their own ideological or policy positions ought to increase the likelihood that they identify with a party and/or strengthen their expressions of partisanship.

Of course, it is possible that, in some cases, additional information or reflection might convince individuals that there is no party out there that does a good job representing them and therefore make them less likely to identify with a party. However, in general, the instrumental approach ought to lead us to expect that anything that makes it easier to distinguish between the positions of different parties on issues should lead to increased rates of party identification. From a revisionist perspective, if you have no information about where parties stand on issues, it should be impossible to distinguish between parties and therefore impossible to have an identification with any of them. Conversely, if you have perfect information about where parties stand in relation to your ideal point, then the only people who should not be able to identify a party closer to them should be individuals who are precisely at the midpoint between two parties. Thus, in expectation, partisanship should be increasing as the clarification of party positions (relative to one's own position) increases.

Having said that, we would not expect the impact of policy information and reasoning to be the same in all cases. The effects of additional policy information or reflection should be greater in situations where people are less familiar with the policy positions that distinguish political parties. For example, in new democracies, voters typically have limited or no experience with the governing performance of the emergent political parties and will be relatively unfamiliar with the parties' platforms. Similarly, when party systems undergo considerable instability, voters will lack information on new parties and/or possess inaccurate information due to shifting coalitions and alignments among old parties. In such cases, new information should have a larger impact on the acquiring and updating of partisanship. At the individual level, within any country at any given time, some individuals will be less familiar with the positions and performance of parties and will have given less thought to their relationship to those parties. Additional policy information and reflection should most assist these individuals in identifying a party to which they belong.

H3: Additional policy information and reflection ought to increase partisanship more in new or unstable party systems than in older, stable party systems, and ought to increase partisanship more among individuals who were previously less familiar with the political parties. 
Consistent with the foregoing hypotheses, prior research has indeed found higher levels of knowledge about political parties, policy, and politics to be associated with both self-reported party identification and behavioral manifestations of partisanship in newer party systems such as Russia (Brader \& Tucker, 2001, 2008; Miller \& Klobucar, 2000). However, other research suggests caution in interpreting the direction of causation between policy perceptions and the strength of partisanship (Bartels, 2002; Carsey \& Layman, 2006; Gerber, Huber, \& Washington, 2010; Highton \& Kam, 2011; Jacoby, 1988; Lenz, 2012; Page \& Jones, 1979). First, there is considerable evidence that individuals often engage in motivated reasoning to see the world as they want it to be, in particular as confirming their predispositions and reaffirming their social identities. Partisanship is a potent source of motivated reasoning, selectively shaping memories, evaluations of government performance, and even perceptions of economic and scientific "facts." In light of this, subjective perceptions that a party's positions align closely with one's own preferences could be an effect, rather than a cause, of party identification. Second, there is a good deal of evidence that parties can influence the policy preferences expressed by their supporters. Evidence of such partisan policy conformity has emerged within the venerable two-party system of the United States (Bolsen, Druckman, \& Cook, 2014; Coan et al., 2008; Cohen, 2003; Druckman, 2001; Kam, 2005; Lenz, 2012) as well as in numerous other old and young democracies (Brader \& Tucker, 2012; Brader, Tucker, \& Duell, 2013; De Sio et al., 2014; Merolla, Stephenson, \& Zechmeister, 2007, 2008; Petersen et al., 2013; Samuels \& Zucco, 2014; Slothuus \& de Vreese, 2010; Sniderman \& Hagendoorn, 2007).

If partisanship influences the policy preferences expressed by voters as well as their perceptions of where the parties stand on those policies, then this makes it more difficult to conclude that perceptions of policy closeness fuel the development of party identification, at the very least on the basis of observational data. Therefore, we aim to examine the impact of policy information and reasoning more directly, by studying what happens through direct intervention in a set of survey experiments. There have been very few experimental studies in which partisanship is the focal outcome of interest. One reason for this is the long-held belief that party identification changes only rarely and slowly, making it difficult to observe short-term changes during an experiment. Nonetheless, even those who have argued that the "glacial stability" proposition is overstated and that short-term updating occurs have not made their case with experimental evidence. One earlier exception lends some credence to these suspicions: Cowden and McDermott (2000) ran two experiments on U.S. college students to test the impact of short-term forces. Neither voting defections nor advocacy for/against presidential impeachment significantly affected party identification in their study, despite plenty of movement in party choice. However, more recent work finds evidence of short-term partisan updating among U.S. adults in national surveys. Across a series of experiments, Groenendyk (2013) shows that, in the face of issue disagreement or disaffection with their own party, partisans will express a weaker sense of party identification, especially when norms of good citizenship are salient or standard partisan defense mechanisms are short-circuited by cognitive overload.

These recent findings notwithstanding, there are serious challenges to studying the causal forces shaping party identification. Although various theoretical models characterize the degree of partisan change differently, all major approaches consider party identification to be a fairly stable attribute and one that is much more stable than most other beliefs and attitudes measured in political science research (Green et al., 2002; Johnston, 2006). In addition, the development (or updating) of partisanship is conceived predominantly as a slow and gradual process that unfolds when social forces or cascades of political information act on identities over long stretches of time. Even the sorts of "short-term shocks" typically posited in the literature as capable of shifting partisan identities-major governmental scandals, unpopular wars, economic recessions, changes in marital status-likely exert their influence through the accumulation of news and new circumstances over periods of months and years, rather than hours or days. Treatments in most surveys or lab experiments will, by their nature, tend to mimic modest daily doses of causal forces that would only accumulate meaningfully with 
repeated reinforcement "in the real world" of politics. This weakness in the treatments may be offset somewhat by the greater concentration and clarity of dosages administered and by the heightened attention of participants in experimental studies, relative to the noisy, distracted routines of daily life.

All of this said, revisionist models have long contended that short-term shifts in partisanship occur as a regular matter in response to policy information and assessments. And Groenendyk's research shows that, under the right conditions at least, such movement can be detected in experimental studies, even among adult citizens of the world's oldest, most stable party system. We noted earlier partisan updating should be more prevalent and thus the potential impact of policy information greater among political neophytes and where parties are newer. With that in mind, we focus our experiments primarily in relatively young and/or unstable party systems, where (at the time of data collection) multiparty competition was less than two decades old and most parties were considerably younger than that. In light of the third hypothesis above, we also keep our eyes open to heterogeneity in effects by level of political knowledge.

\section{Data}

To test the hypotheses, we carried out experiments that were embedded in surveys of nearly 5,000 adult citizens in six countries between 2006 and 2012. The primary aim of these surveys was to understand how partisanship and political attitudes were developing in the relatively young democratic or quasi-democratic party systems of postcommunist Europe. Thus, five of the six countries fall within that region: Bulgaria, Hungary, Moldova, Poland, and Russia. A sixth European country, Great Britain, was included in the investigation for comparison to one of the oldest democracies and second oldest party system in the world (Brader, Tucker, \& Bargsted, 2011).

In Russia, the Levada Center conducted in-person interviews of a probability sample of 376 adult citizens residing in Moscow during the spring of 2006. In Poland, the Center for the Study of Public Opinion conducted in-person interviews with a national probability sample of 607 adult citizens during the summer of 2006. In Hungary, Ipsos-Szonda conducted in-person interviews of a probability sample of 409 adult citizens residing in Budapest during the summer of 2007. In Great Britain, YouGov conducted online interviews with a national sample (excluding North Ireland) of 2,301 adult citizens during the winter of 2009. In Bulgaria, Vitosha Research conducted online interviews with a national sample of 654 adult citizens in the summer of 2011. Participants responded to ads posted on websites whose traffic was estimated to encompass about $36 \%$ of the Bulgarian population, a cross-section that is diverse in terms of age and ethnicity. Finally, in Moldova, the Institute of Marketing and Polls (IMAS-INC) conducted in-person interviews with a national (excluding Transnistria) probability sample of 636 adult citizens in the winter and spring of 2012.

Although carried out by different organizations, construction of the survey questionnaires is very similar across all six countries. In addition to the experiments, the questionnaire includes many questions about the respondent's background and political views. Interviews required between 45 and 60 minutes to complete on average. The focal experiments appear quite early in the survey, preceded by a few questions regarding demographics, interest in politics, and feelings about the way things are going. Following the experimental interventions, there is a lengthy battery of questions about political attitudes, including measures of partisanship that form the key outcomes of interest in the present study. $^{2}$

${ }^{2}$ Later portions of the survey included other experiments-for example, on the impact of party cues-and more questions regarding political attitudes, voting behavior, participation, group attachments, demographics, and personality traits. 


\section{Design of the Experiments}

The surveys include two distinct experiments. The first manipulates exposure to factual information about the substantive policy aims of the major parties and appears in four of the surveys (all except Bulgaria and Moldova). All respondents receive an information card or screen about the names of the major political parties in the country, the names of their current leaders, and reproductions of their party symbols. The half of respondents who are randomly assigned to the information treatment also receive details about each party: ideological proclivities, major policy positions and goals, originating date, and recent incumbency status. Thus, the control group is prompted to learn or remember the basic identity of the major parties, while the treatment group is further informed or reminded about the substantive policy priorities and preferences of the parties, as well as the basic information required to make performance judgments. ${ }^{3}$ Information was provided only about the most important political parties in each country; respondents saw information about six parties in Poland and Russia, and information about four parties in Hungary and Great Britain. ${ }^{4}$

Note two important features of this manipulation. First, the manipulation of information takes the form of balanced information about policy positions. With this design, we want to observe whether exposing citizens to policy-related information that accurately reflects the views of all the major parties (at least as the parties see themselves) assists them in identifying a party that best represents their interests and thereby causes them to update or solidify their partisanship accordingly. We see this as consistent with theories of party identification that focus heavily on the comparison of policy positions and expected policy benefits (Achen, 1989, 1992; Franklin \& Jackson, 1983). ${ }^{5}$ The second feature of this manipulation to notice is that the information is fairly general in nature and modest in amount. The stimulus in this sense is not an especially large "dose" of information, especially compared to what voters may be exposed to during the course of entire election campaigns, let alone years of political attentiveness. However, it is closer to the volume and generality of information that a broad share of the electorate typically digests in a short time period-more than is found, say, in even several political advertisements or in a single news article, perhaps closer to the amount of information conveyed in a debate.

The second experiment is the proximity task. ${ }^{6}$ Half of the respondents were randomly assigned to receive the task. Interviewers asked these treatment respondents to place each of the major parties on a 7-point policy scale. ${ }^{7}$ Respondents then place themselves on the same scale. The procedure is repeated across three issues from distinct policy domains. This task is essentially identical to the sorts of standard survey items many researchers use to test policy-based models with nonexperimental data. Our goal is to examine what thinking through the proximity of parties vis-à-vis oneself over a variety of salient policy domains contributes to partisan learning. Thus, rather than exposing people to policy

${ }^{3}$ This information was drawn from the official website of the party, its platform, and the consensus views of political experts on each country. It was presented as a bullet-point list of facts. See the online supporting information for the replicas of these pages, translated into English.

${ }^{4}$ For comparative purposes, it might be tempting to focus on the same number of parties in each country, but such an emphasis on numerical equivalence would weaken the substantive equivalence in accurately reflecting the party system in each country.

5 An alternative design, perhaps more in line with Fiorina's (1981) model, could be used to assess the impact of performance information about the record of benefits realized from one or more parties. One might anticipate more partyspecific directional effects, if such information is harder to convey in a balanced fashion. Some stimulus materials in this study's information experiment contained reminders about when (how recently) certain parties had controlled the government, which may assist modestly, albeit indirectly, with performance judgments.

${ }^{6}$ Random assignment of the two experiments was done independently. Respondents could receive both, neither, or only one of the two. We did not hypothesize any impact beyond the possibility of additive effects from such an interaction. Analyses turned up no evidence of any meaningful interaction effect from receiving both treatments. As a result, we take up the impact of each experiment separately in the remainder of this article.

${ }^{7}$ The online supporting information contains further examples and details about the substantive content of these questions. 
information, this task requires individuals to reflect on what they believe about the policy positions of parties, evaluate the relative position of several parties, and thereby bring into stark relief which parties are closer and further from the views of the respondent. ${ }^{8}$

\section{Measurement}

For measuring our key outcomes, we rely on multiple indicators to strengthen inferences about the development and effects of partisan identities, especially in new or unstable party contexts where partisanship may be nascent (Brader \& Tucker, 2001, 2008; Green et al., 2002).

We consider five measures. The first, self-identification, is in the spirit of the traditional ANES party-identification measure, modified for use in multiparty, postcommunist studies (cf. Colton, 2000; Colton \& McFaul, 2003). It appears in the survey immediately following the experimental interventions. In four countries (Great Britain, Hungary, Poland, and Russia), this adaptation asks respondents if there is a party they consider "my party" or, as a follow-up, if there is at least some party they believe accurately reflects their "interests, views, and concerns." In the other two countries, the battery of questions more closely approximates the ANES style of asking if the respondent thinks of herself as belonging to, or "identifies with," any of the listed parties. By this measure, $64 \%$ of respondents across all countries identify a party as theirs, ranging from a low of 53\% in Hungary to a high of $80 \%$ in Moldova.

The second measure draws on the same battery to measure strength of self-identification among those who name a party as theirs. The first level of this variable represents those who have typically been labeled as "partisan leaners" in the scholarly literature, by virtue of denying an identity initially and acquiescing only on the follow-up question. Second and third levels derive from a separate question that asks either the degree to which the party reflects their views (partially or completely) or how strongly they identify (not so strongly or strongly). When recoded to range from 0 to 1 , the pooled mean strength score among self-identified partisans is 0.64 (low $=0.56$ in Russia; high $=0.69$ in Moldova).

The third measure, party closeness or closeness identification, has been used extensively across political systems and is the key indicator of partisanship in the cross-national Comparative Study of Electoral Systems (CSES) project:

Do you usually think of yourself as close to any particular party, movement, or association?

[IF YES:] Which party, movement, or association is that? Do you feel very close to this party, somewhat close, or not very close?

[IF NO:] Is there a party to which you feel yourself a little closer than to the others?

[IF YES:] Which party is that? Name it, please. Do you feel very close to this party, somewhat close, or not very close?

This binary close ID measure indicates whether they acknowledge a party as close or "a little bit closer" to them. The related fourth measure reflects the degree or strength of closeness, which is ascertained for any respondent who indicates a close party in either the initial or follow-up question. This battery of questions appears a few minutes later in the survey than the experimental intervention. Questions preceding the battery tap feelings of political efficacy, general views of the party and

${ }^{8}$ In a sense, the first experiment provides respondents with policy information about parties from an external source (for some, this may be novel information, for others a reminder of what they knew previously), while the proximity task "generates" information from an internal source by prompting respondents to consider what they believe about the positions of parties on policy issues. 
political system, and attitudes toward the specific parties, though no additional information about the parties is provided. As such these two measures, in addition to approaching the concept somewhat differently, ought to be a bit noisier than the first two, but these measurement properties are constant across experimental conditions. The closeness item yields a slightly higher though very similar estimate of the share of partisans, with $66 \%$ saying they feel at least a little closer to one party (low $=56 \%$ in Moldova; high $=73 \%$ in Great Britain). ${ }^{9}$ The pooled mean for strength of closeness is 0.62 (low $=0.42$ in Poland; high $=0.71$ in Hungary).

The fifth measure draws on a more recent tradition of attempting to tap the extent of partisan social identification through a battery of questions that assess how closely a respondent is cognitively and affectively in sympathy with a party (cf. Greene, 2002; Huddy et al., 2015; Weisberg \& Greene, 2003). For respondents who previously indicated feeling close to a party, they were asked the degree to which they agree or disagree with five statements:

When I talk about supporters of [party], I usually say "we" rather than "they."

I don't have much in common with supporters of [party]. [reverse coded]

When someone criticizes [party], it feels like a personal insult.

When [party] does well in an election or achieves its goals, I feel very proud.

When [party] does poorly in an election or fails to achieve its goals, I feel very disappointed or upset.

These items are combined to produce a 16-point additive scale of how much an individual internalizes a sense of identity with a party. When recoded to range from 0 to 1 , the pooled mean of partisan social ID among partisans is 0.54 (low $=0.48$ in Poland; high $=0.64$ in Moldova).

Our analyses also require a measure for assessing levels of prior political information, knowledge, or "sophistication" that may moderate which respondents will be most affected by the treatments. In keeping with much of the literature, we construct a measure of political knowledge based on questions that tap general awareness of current political institutions and leadership (Zaller, 1992). These include, for example, questions asking respondents to identify the current occupants of political offices, the size of the lower legislative chamber, and the parties that won legislative seats in the most recent election. Each survey contains a battery of such items - ranging from eight to fifteen in number-that appear toward the end of the interview. ${ }^{10}$ The final measure is the respondent's proportion of correct answers; the average share of correct answers across all individuals surveyed is 59\%. Nine percent of respondents answered all questions correctly, while $4 \%$ answer failed to answer any correctly.

\section{Results of the Policy Information Experiment}

We first look at the impact of exposing citizens to (truthful) information about the policy priorities and positions of the most important political parties in their country. For those who pay little attention to politics, some or most of this information may have been new. For more attentive citizens, the treatment may have served more as a comprehensive reminder of facts stored unevenly in memory. Our interest is in the effect exposure to this policy information has on the acquisition and strength

${ }^{9}$ The value of looking at multiple measures is underscored by at least two observations regarding the descriptive data. First, while the pooled estimates of the share of partisans in the population are very similar (64\% vs. 66\%), variation at the country-level is much greater in some cases, as illustrated by Moldova scoring the highest rate of identification by one measure and the lowest rate by the other. Second, at the individual level, $19 \%$ of respondents identified as partisan on one question but not the other.

${ }^{10}$ We discovered errors in the scoring of two political knowledge questions in the British survey. As a result, those two items are not included in the scale. 


\section{Self ID Effect of Information}

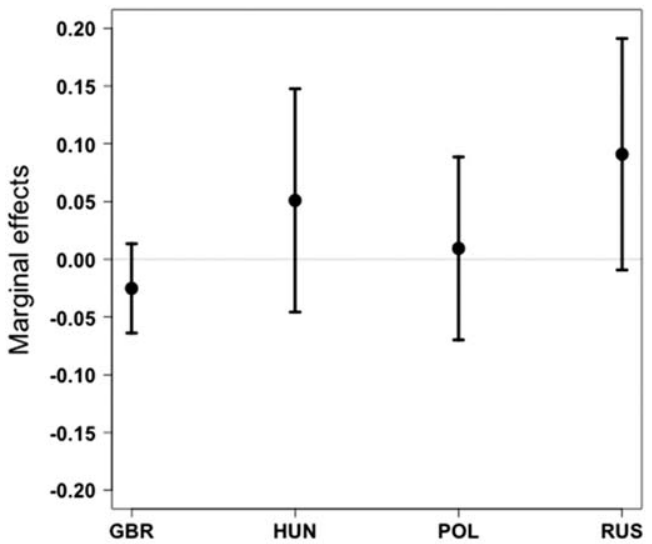

Self Strength Effect of Information

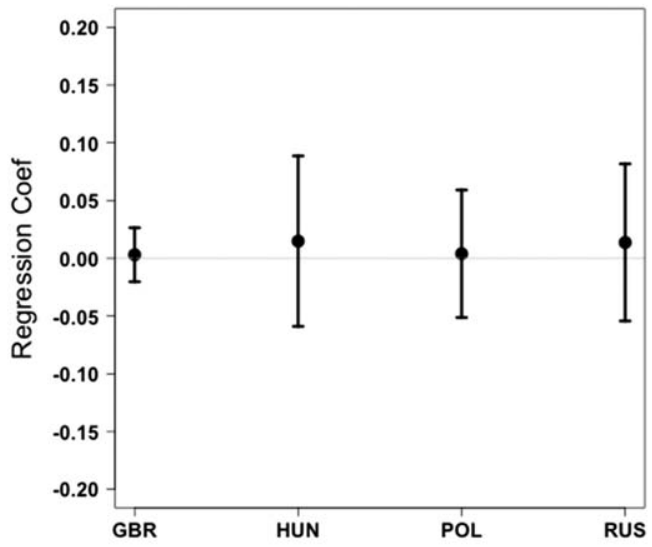

Close ID Effect of Information

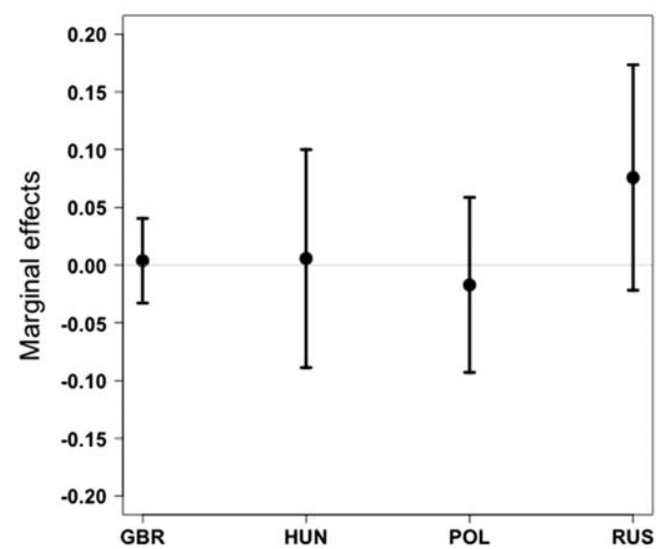

Close Strength Effect of Information

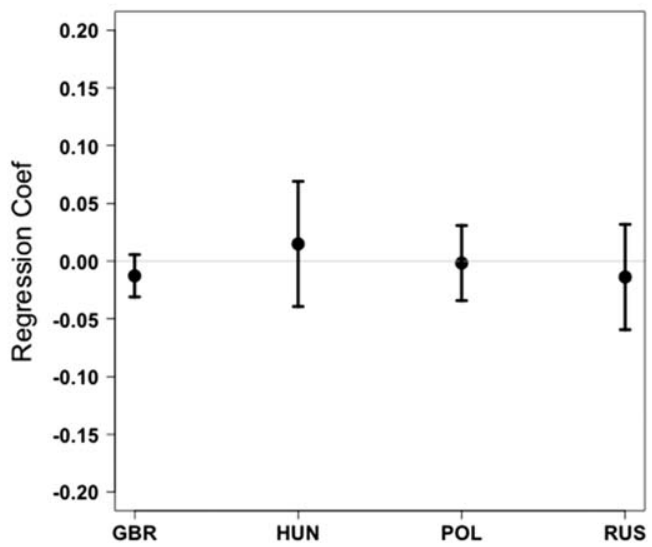

Figure 1. Bivariate effect of information treatment on partisanship, by country. Plots show the direct bivariate effect of the policy information treatment on each outcome measure of partisanship, in each country. Bands represent the $95 \%$ confidence interval around those estimates.

of partisan identities. Hypothesis 1 posits that, on average, such information should increase both partisan acquisition and strength.

Figure 1 shows the simple bivariate effects of the policy information treatment in each of the four countries where this experiment was conducted. ${ }^{11}$ An overall pattern is immediately clear. Across all four outcome measures shown, there is little consistent evidence-indeed little evidence at all-that exposure to systematic policy information about the major parties affects levels of partisanship. In most cases, the observed difference from the control group is zero or a negligible one or two percentage points. The sole exception is Russia, where after a decade of vigorous multiparty competition was beginning to see the relevance of political parties wane due to increasing interference and orchestration by the government of President Vladimir Putin. In this setting, the rate of self-identification was

${ }^{11}$ Unless otherwise noted, all bivariate and multivariate estimates are derived from logistic regression for the binary identification outcome variables and ordinary least squares regression for the partisan strength and social identity scales. 
Table 1. Effects of Policy Information Treatment on Partisanship

\begin{tabular}{|c|c|c|c|c|c|}
\hline & Self-Identification & $\begin{array}{c}\text { Closeness } \\
\text { Identification }\end{array}$ & $\begin{array}{l}\text { Self ID } \\
\text { Strength }\end{array}$ & $\begin{array}{l}\text { Close ID } \\
\text { Strength }\end{array}$ & $\begin{array}{c}\text { Social ID } \\
\text { Partisanship }\end{array}$ \\
\hline Info Treatment & $-0.096(0.154)$ & $-0.134(0.166)$ & $-0.002(0.022)$ & $-0.015(0.016)$ & $-0.011(0.017)$ \\
\hline Political Knowledge & $-0.272(0.186)$ & $-0.548(0.198)^{* * *}$ & $-0.028(0.028)$ & $-0.049(0.021)^{* *}$ & $-0.057(0.022)^{* * *}$ \\
\hline $\begin{array}{l}\text { Treatment } \\
\quad \times \text { Knowledge }\end{array}$ & $0.192(0.250)$ & $0.312(0.266)$ & $0.015(0.036)$ & $0.015(0.026)$ & $0.034(0.028)$ \\
\hline Age & $0.018(0.002)^{* * *}$ & $0.021(0.002)^{* * *}$ & $0.001(0.000)^{*}$ & $0.001(0.000)^{* * *}$ & $0.002(0.000)^{* * *}$ \\
\hline Education & $0.145(0.028)^{* * * *}$ & $0.166(0.030)^{* * *}$ & $-0.009(0.004)^{* *}$ & $0.005(0.003)^{*}$ & $-0.003(0.003)$ \\
\hline Constant & $-0.519(0.199)$ & $-0.298(0.210)$ & $0.642(0.029)$ & $0.586(0.021)$ & $0.455(0.023)$ \\
\hline AIC & $4,757.5$ & $4,369.3$ & & & \\
\hline Adj. $R^{2}$ & & & 0.018 & 0.178 & 0.061 \\
\hline$N$ & 3,660 & 3,632 & 2,262 & 2,514 & 2,206 \\
\hline
\end{tabular}

Note: The table displays coefficients and standard errors from logistic (first two columns) and ordinary least squares (last three columns) regressions. All models include country fixed effects (not shown).

$* p<0.1, * * p<.05, * * * p<.01$.

10 percentage points higher after exposure to the policy information about the parties. A similar, slightly smaller effect is observed later in the survey using the close ID measure. This effect emerged only for the likelihood of identifying with a party. When we look at partisans, there was no effect on the strength of self-identification or strength of closeness. ${ }^{12}$ For the one long-established party system in our study, Great Britain, the effect tilted in a negative direction, opposite of predictions, though the size of shift is substantively minimal. Contrary to Hypothesis 1 , we find little evidence to support the impact of policy information on the likelihood of party identification and no evidence of its impact on strength of partisanship.

Taking advantage of the fact that parallel experiments were carried out across these four countries, we combine the data and revisit the analyses with the pooled sample. Given the bivariate results, it is unlikely that this step will yield markedly different conclusions on the main effect, but it will improve statistical power for multivariate analysis and examination of the potential moderating role of political knowledge. Table 1 reports the pooled estimates of the treatment effect, political knowledge, and the interaction of those two variables across the five outcome measures. These models include controls for age and education, two variables that often correlate with both partisanship and knowledge, as well as fixed effects for country. Unsurprisingly, the pooled multivariate results turn up no evidence of main effects of policy information. Any hint of an interaction effect, which is most visible for the binary identity outcomes and the partisan social identification scale, is modest in size and runs in the opposite of the direction anticipated by Hypothesis 3. The strongest case for the interaction is illustrated in Figure 2, which shows the estimated effect of policy information on partisan social ID across levels of political knowledge. For those with the greatest political expertise, exposure to policy information may have boosted their self-expressed partisanship 2-3\% of the scale. For those most lacking in political knowledge, who might have been presumed to have the most to learn, exposure to the policy information, if any, turns out to deflate modestly their sense of partisanship (again, by $2-3 \%$ of the scale).

In sum, across experiments in four countries, we find little evidence of the short-term partisan updating in response to policy information that instrumental approaches to partisanship led us to expect. Exposing citizens to a brief but systematic overview of the policy priorities and positions that

12 All analyses of partisan strength focus exclusively on those identifying with a party. In other words, we do not include nonidentifiers as the low point of the scales, as is often done with measures of partisan strength. Given that we already examine results on binary identification separately, including nonidentifiers would lessen the independence of the tests and muddy our interpretation of what precisely the treatment is affecting. 


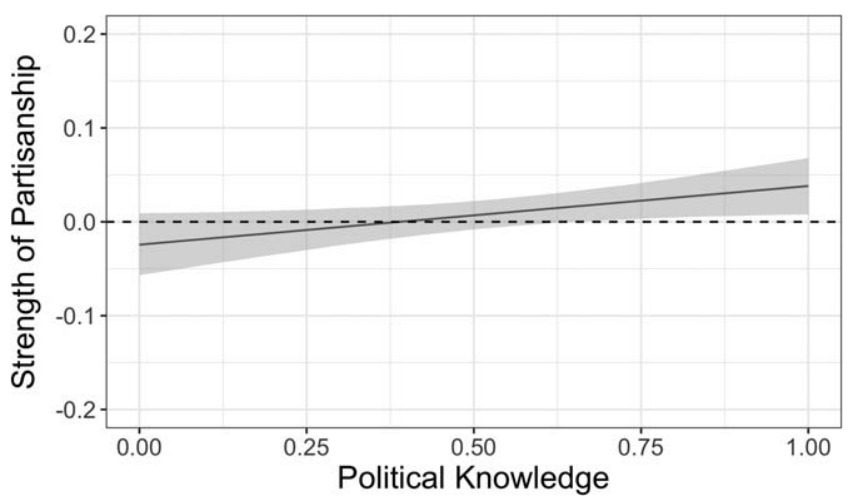

Figure 2. Estimated effect of information treatment on strength of partisan social identification by level of political knowledge. The figure shows the estimated effect of the policy information treatment, across varying levels of political knowledge, on the partisan social identification scale in the pooled cross-national data. The shaded area represents the 95\% confidence interval around those estimates.

distinguish the major political parties mostly has no impact on the likelihood that citizens identify as partisan or how strongly they express their partisanship. Any suggestive evidence of effects we observed was as likely to run in a direction contrary to theoretical predictions as it was to run in the expected directions. Presenting citizens with relevant policy information, even under conditions of high attentiveness, may be insufficient to trigger the sort updating anticipated in instrumental models. Perhaps policy updating of this sort only occurs when citizens are prompted by circumstances to reflect more deeply on the comparisons between parties and to take notice of which parties most closely align with their own views. Our next set of experiments was designed to assess just that possibility.

\section{Results of the Proximity Task Experiment}

Revisionist, instrumental models of partisanship argue that citizens update their partisan identities on the basis of comparing the benefits expected to flow from the policies pursued by each of the major political parties. The more closely any given party's policies are perceived to align with the views and interests of a citizen, the more likely the citizen is to identify as a partisan of that party. Although most proponents of the revisionist approach would not contend that citizens in fact pause to engage in such comprehensive comparisons and computations at any single moment in time, the models are predicated on the view that bits and pieces of reasoning carried out over time approximate such systematic policy assessments. Our second set of experiments aims to investigate what happens when citizens are prompted to engage in this sort of policy reasoning. We ask whether, especially in contexts of relatively new parties and among previously inattentive citizens, such policy reasoning facilitates party identification and/or the strengthening of partisan bonds.

Figure 3 shows the simple bivariate effect of the proximity task treatment in each of the six countries where this experiment was conducted. For partisan self-identification, a fairly clear pattern emerges: Respondents randomly assigned to answer a series of questions about where they and the political parties stand on major issues are less likely to claim a partisan identity. We observe this drop in party identifiers in all six countries. The likelihood of self-identification decreases between 2 and 10 percentage points, with the biggest drops in Hungary and Great Britain and the smallest in Bulgaria. These results run directly contrary to the expectations in Hypothesis 2. Asking citizens to engage in the sort of spatial policy reasoning that underlies most instrumental accounts of partisanship makes it less, rather than more, likely citizens will call any party their own. This pattern repeats for 
Self ID Effect of Proximity

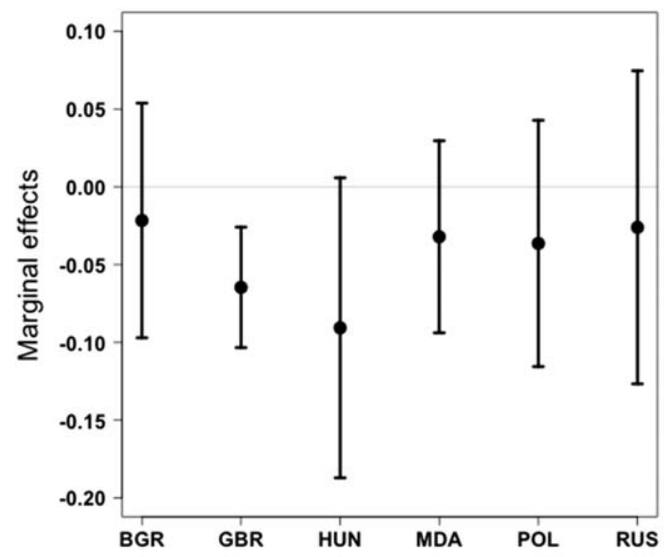

Close ID Effect of Proximity

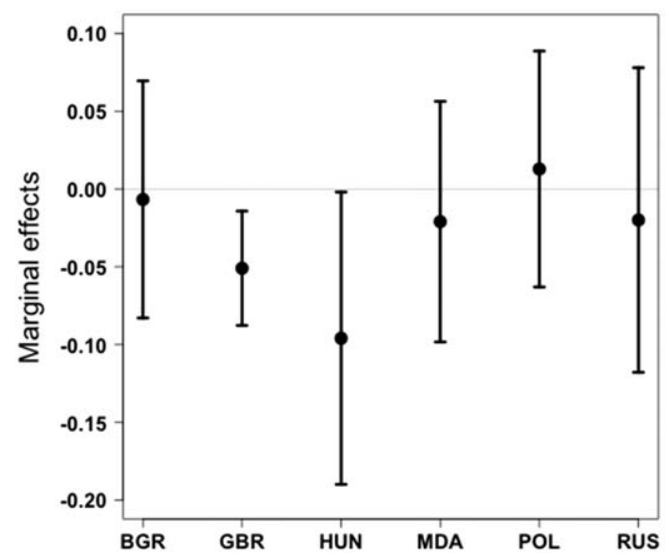

Self Strength Effect of Proximity

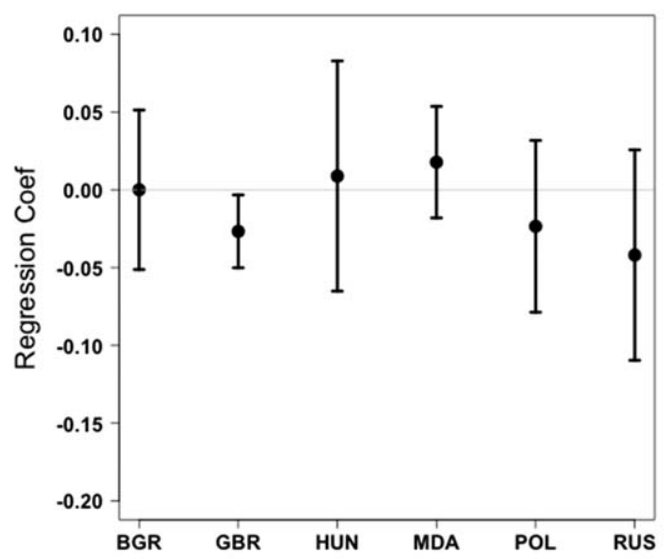

Close Strength Effect of Proximity

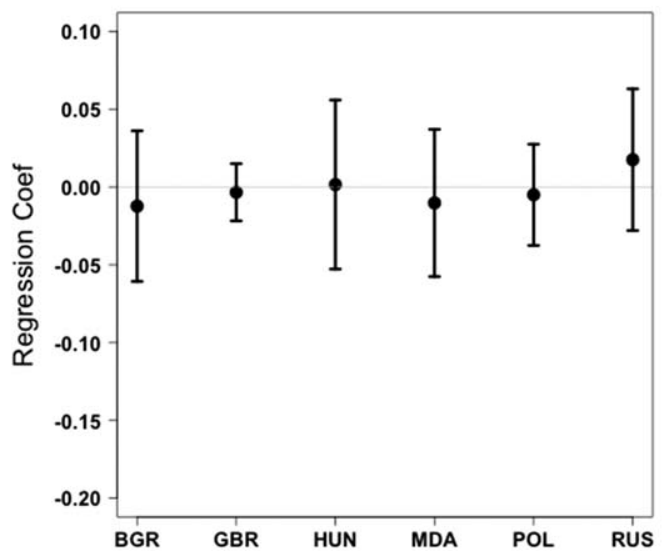

Figure 3. Bivariate effect of proximity task treatment on partisanship, by country. Plots show the direct bivariate effect of the proximity task treatment on each outcome measure of partisanship, in each country. Bands represent the $95 \%$ confidence interval around those estimates.

the second, later measure of partisanship (close ID), though the findings are somewhat attenuated. We still observe a substantial drop, after treatment, among citizens in Hungary and Great Britain, but the drop in Bulgaria, Moldova, and Russia is less certain and edging close to zero in magnitude. The treatment effect for close ID in Poland is slightly positive but also near zero.

There is also some evidence that the proximity task treatment affected the strength of partisanship expressed among party identifiers. We see a 2-5 percentage-point drop in the strength of self-identifcation in Great Britain, Poland, and Russia, a small boost in strength in Moldova, and no change in Bulgaria and Hungary. Later on, the survey registers mostly no change in the strength of closeness felt among those who identify as partisan identifiers (close ID). The effect is essentially zero in five of the countries, but slightly positive in Russia. Overall, the pattern of treatment effects is more mixed when it comes to partisan strength and, if anything, tilts somewhat in the direction of a negative impact. Hypothesis 2 thus finds little support in these data as well. 
Table 2. Effects of Proximity Task Treatment on Partisanship

\begin{tabular}{|c|c|c|c|c|c|}
\hline & Self-Identification & $\begin{array}{c}\text { Closeness } \\
\text { Identification }\end{array}$ & Self ID Strength & Close ID Strength & $\begin{array}{c}\text { Social ID } \\
\text { Partisanship }\end{array}$ \\
\hline $\begin{array}{l}\text { Proximity } \\
\text { Treatment }\end{array}$ & $-0.241(0.143)^{*}$ & $-0.185(0.149)$ & $-0.050(0.020)^{* *}$ & $-0.007(0.016)$ & $-0.005(0.016)$ \\
\hline $\begin{array}{l}\text { Political } \\
\quad \text { Knowledge }\end{array}$ & $-0.042(0.168)$ & $-0.172(0.172)$ & $-0.018(0.024)$ & $-0.015(0.020)$ & $0.004(0.021)$ \\
\hline $\begin{array}{l}\text { Treatment } \times \\
\quad \text { Knowledge }\end{array}$ & $0.031(0.221)$ & $0.046(0.225)$ & $0.058(0.030)^{*}$ & $0.006(0.025)$ & $-0.003(0.026)$ \\
\hline Age & $0.015(0.002)^{* * *}$ & $0.016(0.002)^{* * *}$ & $0.001(0.000)^{* *}$ & $0.001(0.000)^{* * *}$ & $0.002(0.000)^{* * *}$ \\
\hline Education & $0.094(0.025)^{* * *}$ & $0.129(0.025)^{* * *}$ & $-0.008(0.003)^{* *}$ & $0.006(0.003)^{* *}$ & $-0.001(0.003)$ \\
\hline Constant & $-0.580(0.208)$ & $-0.734(0.211)$ & $0.688(0.029)$ & $0.594(0.024)$ & $0.467(0.026)$ \\
\hline AIC & $6,274.8$ & $6,134.5$ & & & \\
\hline Adj. $\mathrm{R}^{2}$ & & & 0.031 & 0.137 & 0.076 \\
\hline$N$ & 4,948 & 4,909 & 3,159 & 3,243 & 2,849 \\
\hline
\end{tabular}

Note: The table displays coefficients and standard errors from logistic (first two columns) and ordinary least squares (last three columns) regressions. All models include country fixed effects (not shown).

$* p<0.1$, ** $p<.05$, *** $p<.01$.

As we did with the previous experiment, let us turn to examining the pooled multivariate estimates and the potential moderating role of political knowledge. The results for five outcome measures are shown in Table 2. These empirical models again include controls for age and education, as well as country fixed effects. The results show significant negative treatment effects for partisan self-identifcation and strength of self ID, with the estimate for close ID also substantially in the negative direction. Given the presence of the interaction term, we can interpret this first row of coefficients in Table 2 as the effect among those who possess the least political knowledge. There does not appear to be a strong or consistent interaction effect across the partisan measures, but such interpretations can be tricky from the coefficients alone.

To aid with interpretation, Figure 4 and Figure 5 plot the estimated effects of the proximity task treatment, across levels of political knowledge, on the likelihood of identifying with a party and on the strength of partisanship among identifiers, respectively. ${ }^{13}$ Figure 4 shows a main negative effect on party identification for answering the battery of policy-placement questions, but not much evidence that the impact is conditional on political knowledge. If anything, the rate of identification is lower after treatment for those with the least knowledge, but the difference by knowledge is not substantively meaningful nor estimated with much certainty. Instead, both political experts and novices are less likely to identify with parties after engaging in this sort of policy reasoning. That holds across the entire spectrum for the initial measure of partisan self ID and holds with greatest confidence across the middle knowledge quartiles for close $I D$. For strength of partisanship, Figure 5 shows our clearest evidence of an interaction between the treatment and knowledge on strength of self ID and no effect of any sort for closeness strength. The top plot looks similar to the interaction observed earlier for the policy-information treatment in Figure 2. In this case, the proximity treatment has no effect on partisan strength among expert partisans, but a negative impact on partisan strength among novice partisans. As in preceding experiment, these results either fail to support or directly contradict the expectations of Hypothesis 3.

In contrast to the findings of the policy-information experiment, we do find some evidence of short-term partisan updating in response to the proximity task experiment conducted in six countries. However, the nature of that effect runs directly contrary to the expectations of the

${ }^{13}$ We omit a plot for the partisan social ID scale for space considerations. There are no main or interaction effects suggested for that outcome. The plot looks indistinguishable from the plot for closeness strength in Figure 5. 

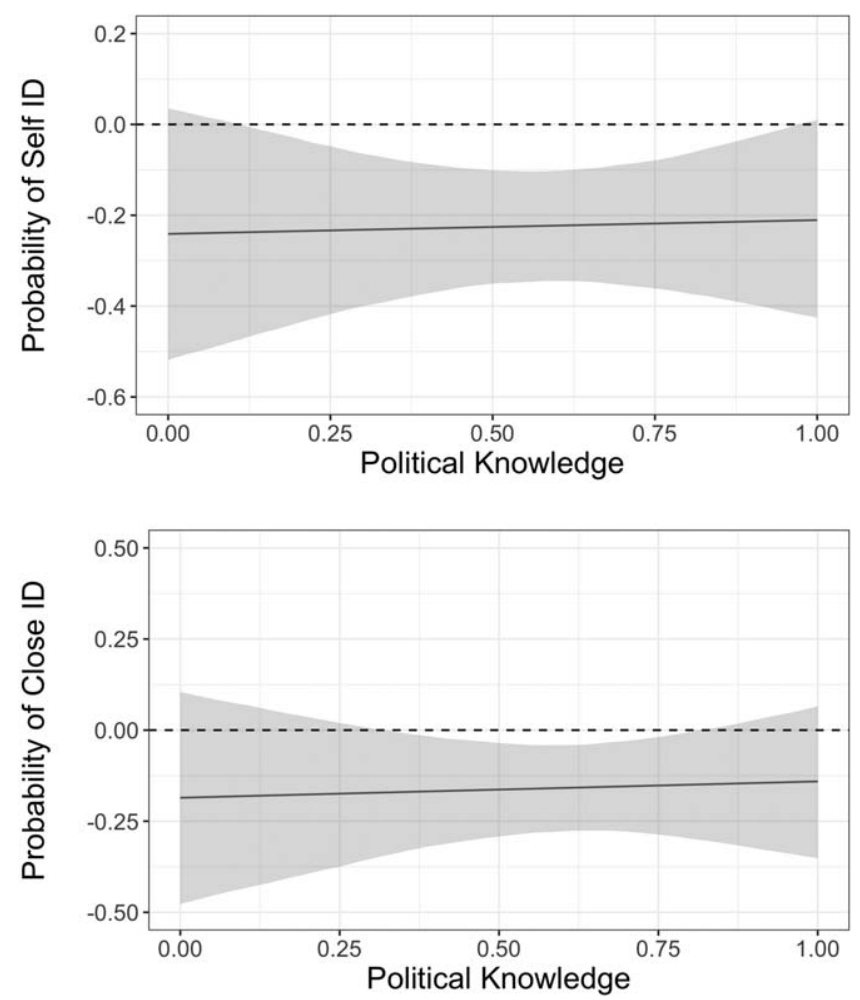

Figure 4. Estimated effect of proximity task treatment on party identification by level of political knowledge. The figure shows the estimated effect of the proximity task treatment, across varying levels of political knowledge, on the likelihood of partisan self-identification (top) and closeness identification (bottom) in the pooled cross-national data. The shaded area represents the $95 \%$ confidence interval around those estimates.

instrumental approaches to partisanship. Asking citizens to think about where they and each of the major political parties is positioned on a set of key policy domains immediately depresses the likelihood that citizens identify as partisan as well as the strength of attachment partisans express. The latter effect occurs particularly among those partisans who are least likely to have spent time reflecting on matters of party and policy prior to this study. Apparently, this sort of policy-based reasoning about political parties does not facilitate the development of partisanship but instead undermines it—weakening the party attachments citizens had already developed, presumably through some other process.

\section{Discussion}

We set out to examine the impact of policy evaluations on the development of political partisanship. In particular, we investigated whether information about policy differences among political parties as well as explicit assessments of which parties most closely share a person's policy views - core building blocks in instrumental approaches to partisanship and voting-facilitate the acquisition and solidification of party identification. Prior research has found strong associations between such policy information or perceptions and self-reported partisanship, but there is considerable uncertainty about the causal direction of this association. In light of this, we designed a pair of survey experiments to observe more directly and confidently the causal impact from policy information and reasoning on short-term partisan updating. Moreover, we sought evidence of such effects where they ought to be 

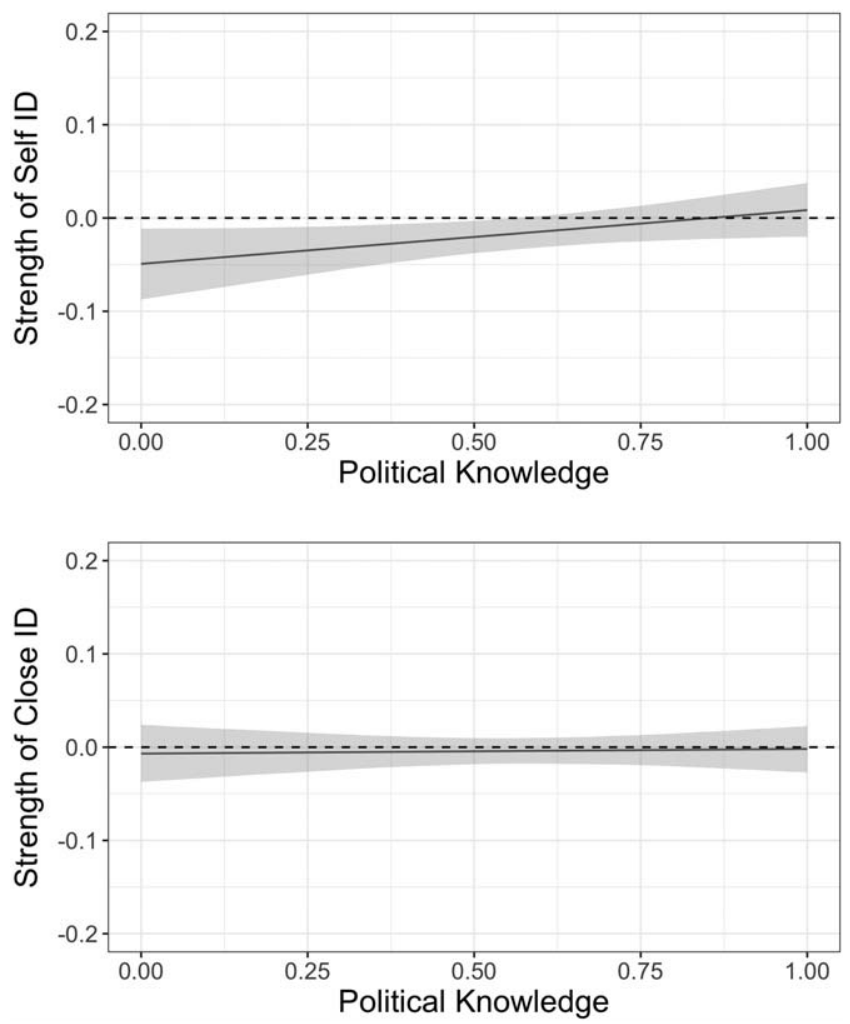

Figure 5. Estimated effect of proximity task treatment on strength of partisanship by level of political knowledge. The figure shows the estimated effect of the proximity task treatment, across varying levels of political knowledge, on the strength of partisan self-identification (top) and strength of closeness identification (bottom) in the pooled cross-national data. The shaded area represents the $95 \%$ confidence interval around those estimates.

easiest to observe, among citizens who know less about politics from the outset and who live in countries where party competition and the political parties themselves are relatively new. Ultimately, we gathered data on nearly 5,000 adult citizens from five young democracies and one venerable democracy.

The results taken together strongly suggest that policy information and reasoning do not help and may in fact hurt the development of partisan identities. These findings run strikingly counter to the expectations derived from revisionist instrumental models of partisanship. Exposure to policy information - a brief but fairly comprehensive summary of the major policy differences between major political parties - mostly has no impact on reports of partisanship. At the country level, the sole exception is evidence of a positive impact of policy information on party identification in Russia. That is the only finding consistent with the instrumental accounts in any of our experiments. There also is evidence that policy information modestly strengthens the sense of social identification among expert partisans, yet weakens it among novice partisans - an intriguing finding that runs in the opposite direction of theoretical expectations. Policy reasoning, in the form of placing oneself and each of the political parties on a series of spatial policy scales, decreases rates of party identification and weakens reports of partisan strength. The impact on identification occurs irrespective of political knowledge, but the negative effect on strength emerges primarily among novice partisans. Finally, there are no clear differences by age or stability of party system; the surprising negative impact of 
policy reasoning appears in countries where the parties are decades old as well as countries where parties are on average only a few years old. ${ }^{14}$

This article thus yields predominantly "negative findings" in so far as we uncover little or no support for any of the hypotheses we set out to test in this study. Such (non-)findings, even when they speak directly to prior theoretical claims, have traditionally faced obstacles to publication, whether in the form of manifest resistance during peer review (e.g., deeming such "null results" as insufficiently exciting to merit space in important journals) or authors simply failing to pursue publication because they assume they will encounter such resistance. Fortunately, in recent years social scientists have become increasingly attentive to the potential perniciousness of this "file-drawer problem" for the accumulation of knowledge and therefore to the importance of disseminating findings regardless of whether they confirm or fail to confirm hypotheses.

Still, there are a number of reasons why one could find negative or null results even if the "true" relationship were present in the world, and we would be remiss in not addressing them before concluding. First, there is the possibility that it is simply impossible to move such a powerful force as political partisanship as a result of a single survey experiment. Here, we are reassured by the fact that Groenendyk (2013) carried out survey experiments in which he indeed found changes in partisanship from stimuli over the course of an experiment. Second, it is possible that our experiments were simply not strong enough to trigger a change in self-reported partisanship. That is not exactly what we found, however. In several cases, we found statistically significant results in the opposite direction from what we expected to find, suggesting that there is nothing inherent in the design of the experiment that guarantees a null result. Furthermore, the fact that we found null or contrary findings across six different countries makes us more confident that we are not simply picking up idiosyncrasies of a particular political context, unusual sample, or botched experimental administration. All that said, there are undoubtedly other ways to devise experimental tests of the proposition that party identification is built from instrumental policy assessments. We hope our failure to find support for that proposition, despite investing considerable effort and resources to assess it directly, motivates researchers to carry out additional, perhaps better experimental tests that can help either solidify the insights obtained here or, alternatively, set the record straight on our mistaken conclusions. ${ }^{15}$

Stepping back from questions of what other studies might reveal, the evidence we have on hand now suggests that policy information and instrumental policy reasoning do not provide the principal foundation for the partisan identities of most citizens. When tasked with reflecting on such information, citizens may even retract from existing partisan attachments. Why does reflecting on the policy proximity of parties drive people away from partisanship? We cannot answer that question with confidence based on the data presented here. In retrospect, prior research in social psychology provides some further reasons for pause before signing onto the otherwise intuitive connection between policy beliefs and partisanship suggested by the revisionist approach. A multitude of studies point to humans as (1) often forming preferences hastily through "gut reactions" to the objects under consideration and

14 These negative results parallel unpublished findings from pilot experiments conducted by the authors on American college students. The procedure differed substantially from the proximity task experiment reported here and involved asking students to elaborate on their reasons for liking and disliking the political parties. After engaging in this reflective task about their preferred party, students reported diminished levels of partisanship. This was especially true of those with less political knowledge.

${ }^{15}$ It is possible that a field experiment carried out over a much longer duration, and thus allowing for accumulation of repeated stimuli, could provide a more convincing demonstration of substantial and sustained movements in partisanship. We suspect such an experiment would raise serious ethical concerns about the proper use of academic resources and run into challenges from institutional review boards, though it might be feasible if researchers partnered carefully with a political organization already attempting to influence partisan identities. (However, see Gerber et al. 2010, for an example of a field experiment that induced an increase in self-reported partisanship by reminding voters to register with a political party for an upcoming intraparty vote—suggesting that formal declarations of affiliation increase psychological identification.) 
(2) doing a poor job at introspecting about the reasons or basis for their judgments (Damasio, 1994; Lau \& Redlawsk, 2001; Wilson, Kraft, \& Dunn, 1989; Wilson et al. 1993; Wilson \& Schooler, 1991).

It is possible, therefore, that presenting individuals with a large batch of information about the policy positions of parties or prompting them to reflect systematically about where they stand on issues vis-à-vis parties may steer them away from their prior (or, potentially, "true") partisan preferences. Subjecting what is ordinarily an object of unreflective attachment to greater scrutiny and rumination may invite citizens to second guess, at least momentarily, their partisan convictions. Or, perhaps, a series of questions requiring respondents to place each of the parties on a few different issues is a difficult task for many citizens, especially those who know less about politics in the first place. As such, the task may generate embarrassment and self-doubt that spills over into subsequent reports of partisanship. That said, given the ample evidence in other studies of partisan-motivated reasoning and projecting preferred parties as closer, one might equally well have assumed that the proximity task would provide an occasion for bolstering party identities (cf. Groenendyk, 2013). Regardless, we can only speculate about such matters at present; further illumination of mechanisms must await future study.

\section{ACKNOWLEDGMENTS}

We thank the many individuals who offered advice and assistance over the course of this project. Daniel Hiaeshutter-Rice provided invaluable assistance with the final rounds of data analysis. Financial support for the data collection was generously provided by Office of the Vice-President for Research and the Center for Political Studies at the University of Michigan, the New York University Research Challenge Fund, the Princeton Institute for International and Regional Studies, and the U.S. Department of State's Title VIII grant program administered through the University of Delaware. Correspondence concerning this article should be addressed to Ted Brader, Institute for Social Research (ISR), University of Michigan, 426 Thompson Street, Ann Arbor, MI 48104. E-mail: tbrader@umich.edu

\section{REFERENCES}

Achen, C. H. (1992). Social psychology, demographic variables, and linear regression: Breaking the iron triangle in voting research. Political Behavior, 14(3),195-211.

Achen, C. H. (2002). Parental socialization and rational party identification. Political Behavior, 24(2), 151-170.

Aldrich, J. H. (1995). Why parties? The origin and transformation of political parties in America. Chicago, IL: University of Chicago Press.

Bartels, L. (2002). Beyond the running tally: Partisan bias in political perceptions. Political Behavior, 24(2), 117-150.

Berelson, B. R., Lazarsfeld, P. F., \& McPhee, W. N. (1954). Voting: A study of opinion Formation in a presidential campaign. Chicago, IL: University of Chicago Press.

Bolsen, T., Druckman, J. N., \& Cook, F. L. (2014). The influence of partisan motivated reasoning on public opinion. Political Behavior, 36, 235-262.

Brader, T., \& Tucker, J. A. (2001). The emergence of mass partisanship in Russia, 1993-1996. American Journal of Political Science, 45(1), 69-83.

Brader, T., \& Tucker, J. A. (2008). Pathways to partisanship: Evidence from Russia. Post Soviet Affairs, 24(3), 263-300.

Brader, T., \& Tucker, J. A. (2012). Following the party's lead: Party cues, policy opinion, and the power of partisanship in three multiparty systems. Comparative Politics, 44(4), 403-420.

Brader, T., Tucker, J. A., \& Bargsted, M. (2011). Of time and partisan stability revisited. Paper presented at the annual meeting of the European Political Science Association, Dublin, Ireland.

Brader, T., Tucker, J. A., \& Duell, D. (2013). Which parties can lead opinion? Experimental evidence on partisan cue taking in multiparty democracies. Comparative Political Studies, 46(11), 1485-1517.

Campbell, A., Converse, P. E., Miller, W. E., \& Stokes, D. E. (1960). The American voter. New York, NY: Wiley. 
Carsey, T. M., \& Layman, G. C. (2006). Changing sides or changing minds? Party identification and policy preferences in the American electorate. American Journal of Political Science, 50(2), 464-477.

Coan, T., Merolla, J., Stephenson, L., \& Zechmeister, E. (2008). It's not easy being green: Minor party labels as heuristic aids. Political Psychology, 29(3), 389-405.

Cohen, G. (2003). Party over policy: The dominating impact of group influence on political beliefs. Journal of Personality and Social Psychology, 85, 808-822.

Colton, T. J. (2000). Transitional citizens: Voters and what influences them in the new Russia. Cambridge, MA: Harvard University Press.

Colton, T. J., \& McFaul, M. (2003). Popular choice and managed democracy: The Russian elections of 1999 and 2000. Washington, DC: Brookings Institution Press.

Converse, P. E. (1969). Of time and partisan stability. Comparative Political Studies, 2(2), 139-171.

Cowden, J. A., \& McDermott, R. (2000). Short-term forces and partisanship. Political Behavior, 22(3), $197-222$.

Damasio, A. R. (1994). Descartes' error. New York, NY: G. P. Putnam.

De Sio, L., Paparo, A., Tucker, J. A., \& Brader, T. (2014). Do parties still orient voters in times of crisis? Evidence of partisan cueing effects in 2013 Italy. In L. Bardo, H. Kriesi, \& A. H. Trechsel (Eds.), Elections in Europe in times of crisis (pp. 11-34). Florence, Italy: European University Institute.

Druckman, J. N. (2001). Using credible advice to overcome framing effects. Journal of Law, Economics, and Organization, 17(1), 62-82.

Fiorina, M. P. (1981). Retrospective voting in American national elections. New Haven, CT: Yale University Press.

Franklin, C. H. (1984). Issue preferences, socialization, and the evolution of party identification. American Journal of Political Science, 28, 459-478.

Franklin, C. H., \& Jackson, J. E. (1983). The dynamics of party identification. American Political Science Review, 77, 957-973.

Gerber, A., \& Green, D. P. (1998). Rational learning and partisan attitudes. American Journal of Political Science, 42(3), 794-818.

Gerber, A., Huber, G., \& Washington, E. (2010). Party Affiliation, Partisanship, and political beliefs: A field experiment. American Political Science Review, 104(4), 720-744.

Green, D. P., Palmquist, B., \& Schickler, E. (2002). Partisan hearts and minds: Political parties and the social identities of voters. New Haven, CT: Yale University Press.

Greene, S. (2002). The social-psychological measurement of partisanship. Political Behavior, 24(3), 171-197.

Greenstein, F. I. (1965). Children and politics. New Haven, CT: Yale University Press.

Groenendyk, E. W. (2013). Competing motives in the partisan mind: How loyalty and responsiveness shape party identification and democracy. New York, NY: Oxford University Press.

Highton, B., \& Kam, C. D. (2011). The long-term dynamics of partisanship and issue orientations. Journal of Politics, 73(1), 202-215.

Huddy, L., Mason, L., \& Aarøe, L. (2015). Expressive partisanship: Campaign involvement, political emotion, and partisan identity. American Political Science Review, 109(1), 1-17.

Jackson, J. E. (1975). Issues, parties, and presidential votes. American Journal of Political Science, 19, 161-185.

Jacoby, W. G. (1988). The impact of party identification on issue attitudes. American Journal of Political Science, 32(3), 643-661.

Jacoby, W. G. (2011). Attitude organization in the mass public: The impact of ideology and partisanship. In R. Y. Shapiro \& L. R. Jacobs (Eds.), The Oxford handbook of American public opinion and media (pp. 436-451). New York, NY: Oxford University Press.

Jennings, M. K., Stoker, L., \& Bowers, J. (2009). Politics across generations: Family transmission reexamined. Journal of Politics, 71(3), 782-799.

Johnston, R. (2006). Party identification: Unmoved mover or sum of preferences? Annual Review of Political Science, 9 , $329-351$.

Kam, C. D. (2005). Who toes the party line? Cues, values, and individual differences. Political Behavior, 27(2), 163-182.

Lau, R., \& Redlawsk, D. (2001). Advantages and disadvantages of cognitive heuristics in political decision making. American Journal of Political Science, 45(4), 951-971.

Lazarsfeld, P. F., Berelson, B., \& Gaudet, H. (1944). The people's choice. New York, NY: Duell, Sloan, and Pearce.

Lenz, G. (2012). Follow the leader? How voters respond to politicians' performance and policies. Chicago, IL: University of Chicago Press. 
Lewis-Beck, M., Jacoby, W., Norpoth, H., \& Weisberg, H. (2008). The American voter revisited. Ann Arbor: University of Michigan Press.

Lodge, M., \& Hamill, R. (1986). A partisan schema for political information processing. American \& Political Science Review, 80(2), 505-520.

MacKuen, M., Erikson, R., \& Stimson, J. (1989). Macropartisanship. American Political Science Review, 83(4), $1125-1142$.

Merolla, J. L., Stephenson, L. B., \& Zechmeister, E. J. (2007). La aplicación de los méto-dos experimentales en el estudio de los atajos informativos en México [Applying experimental methods to the study of information shortcuts in Mexico]. Politica y Gobierno, 14(1), 117-142.

Merolla, J. L., Stephenson, L. B., \& Zechmeister, E. J. (2008). Can Canadians take a Hint? The (in)effectiveness of party labels as information shortcuts in Canada. Canadian Journal of Political Science/Revue Canadienne de Science Politique, 41(3), 673-696.

Miller, A. H., \& Klobucar, T. F. (2000). The development of party identification in post-society societies. American Journal of Political Science, 44(4), 667-686.

Miller, W. E., \& Shanks, J. M. (1996). The new American voter. Cambridge, MA: Harvard University Press.

Niemi, R., \& Jennings, M. K. (1991). Issues and inheritance in the formation of party identification. American Journal of Political Science, 35(4), 970-988.

Page, B. I., \& Jones, C. C. (1979). Reciprocal effects of policy preferences, party loyalties, and the vote. American Political Science Review, 73, 1071-1090.

Petersen, M. B., Skov, M., Serritzlew, S., \& Ramsøy, T. (2013). Motivated reasoning and political parties: Evidence for increased processing in the face of party cues. Political Behavior, 35, 831-854.

Samuels, D., \& Zucco, C. (2014), The power of partisanship in Brazil: Evidence from survey experiments. American Journal of Political Science, 58, 212-225.

Shively, W. P. (1979). The development of party identification among Adults: Exploration of a functional model. American Political Science Review, 73(4), 1039-1054.

Slothuus, R., \& de Vreese, C. (2010). Political parties, motivated reasoning, and issue framing effects. Journal of Politics, 72(3), 630-645.

Sniderman, P. M., \& Hagendoorn, A. (2007). When ways of life collide: Multiculturalism and its discontents in the Netherlands. Princeton, NJ: Princeton University Press.

Weisberg, H., \& Greene, S. (2003). The political psychology of party identification. In M. MacKuen \& G. Rabinowitz (Eds.), Electoral democracy (pp. 83-124). Ann Arbor: University of Michigan Press.

Wilson, T. D., Kraft, D., \& Dunn, D. S. (1989). The disruptive effect of explaining attitudes: The moderating effect of knowledge about the attitude object. Journal of Experimental Social Psychology, 25(5), 379-400.

Wilson, T. D., Lisle, D. J., Schooler, J. W., Hodges, S. D., Klaaren, K. J., \& LaFleur, S. J. (1993). Introspecting about reasons can reduce post-choice satisfaction. Personality and Social Psychology Bulletin, 19(3), 331-339.

Wilson, T. D., \& Schooler, J. W. (1991). Thinking too much: Introspection can reduce the quality of preferences and decisions. Journal of Personality and Social Psychology, 60(2), 181-192.

Zaller, J. (1992). The nature and origins of mass opinion. New York, NY: Cambridge University Press.

Zuckerman, A. S., Dasovic, J., \& Fitzgerald, J. (2007). Partisan families: The social logic of bounded partisanship in Germany and Britain. New York, NY: Cambridge University Press.

\section{SUPPORTING INFORMATION}

Additional supporting information may be found in the online version of this article at the publisher's website:

Full Multivariate Models and Additional Analyses

Question Wording and Experimental Instruments 